\title{
Why Are Life-Cycle Earnings Profiles Getting Flatter?
}

\author{
B. Ravikumar and Guillaume Vandenbroucke
}

\begin{abstract}
The authors present a simple, two-period model of human capital accumulation on the job and through college attainment. They use a calibrated version of the model to explain the observed flattening of the life-cycle earnings profiles of two cohorts of workers. The model accounts for more than 55 percent of the observed flattening for high school-educated and for college-educated workers. Two channels generate the flattening in the model: selection (or higher college attainment) and a higher skill price for the more recent cohort. Absent selection, the model would have accounted for no flattening for high school-educated workers and about 23 percent of the observed flattening for college-educated workers. (JEL E20, I26, J24, J31)
\end{abstract}

Federal Reserve Bank of St. Louis Review, Third Quarter 2017, 99(3), pp. 245-57. https://doi.org/10.20955/r.2017.245-257

\footnotetext{
B. Ravikumar is a vice president and deputy director of research and Guillaume Vandenbroucke is a research officer and economist at the Federal Reserve Bank of St. Louis.

( ) 2017, Federal Reserve Bank of St. Louis. The views expressed in this article are those of the author(s) and do not necessarily reflect the views of the Federal Reserve System, the Board of Governors, or the regional Federal Reserve Banks. Articles may be reprinted, reproduced, published, distributed, displayed, and transmitted in their entirety if copyright notice, author name(s), and full citation are included. Abstracts, synopses, and other derivative works may be made only with prior written permission of the Federal Reserve Bank of St. Louis.
} 


\section{Table 1}

\section{Earnings Growth Data}

\begin{tabular}{lcc} 
& High school & College \\
\hline 1940 Cohort earnings growth & 2.22 & 2.52 \\
\hline 1980 Cohort earnings growth & 1.31 & 1.84 \\
\hline$\%$ Flattening & 40.7 & 26.9 \\
\hline
\end{tabular}

SOURCE: Integrated Public Use Microdata Series (IPUMS) and authors' calculations. Synthetic cohort, employed white men. The 1940 cohort consists of workers aged 20-39 in 1940, and the 1980 cohort consists of workers aged 20-39 in 1980.

the 1940 cohort. 2 Even though our focus is on only two cohorts and two education groups, the flattening of life-cycle earnings profiles is a more pervasive phenomenon. For evidence of flattening in earnings profiles for other cohorts, demographic groups, education groups, and finer age groups, see Kong, Ravikumar, and Vandenbroucke (2016).

In this paper, we present a simple, two-period model that attempts to quantitatively explain the flattening of life-cycle profiles. We use the framework of Ben-Porath (1967), which has been used extensively in the life-cycle earnings literature; see, for example, Heckman, Lochner, and Taber (1998) and Huggett, Ventura, and Yaron (2011). Workers accumulate human capital on the job and increase their earnings over the life cycle. The on-the-job human capital accumulation technology exhibits diminishing returns. Workers are heterogeneous in their endowed ability to accumulate human capital, and those with higher ability accumulate more human capital. Workers are partitioned by ability into two groups: high school educated and college educated. Those below a threshold level of ability are labeled high school educated, and the rest are labeled college educated. High school-educated workers begin their work lives right away with an exogenously given human capital that is positively correlated with their ability. College-educated workers begin their work lives later and decide how much human capital they want at the start of their work lives by choosing an amount of (goods) expenditures while in college. We will show later that for college-educated workers this implies a positive correlation between ability and (endogenous) start-of-work-life human capital.

Two well-known implications of the Ben-Porath model are important for our cross-cohort results. First, diminishing returns imply that workers with higher initial human capital accumulate on-the-job human capital at a slower rate and therefore experience slower earnings growth. Second, ability has two opposing effects on earnings growth. On the one hand, higher ability implies faster on-the-job human capital accumulation and hence higher earnings growth. This is the direct effect of ability. On the other hand, higher-ability workers also have higher human capital at the start of their work lives and hence experience slower earnings growth. In our quantitative exercise, the direct effect of ability dominates.

There are two exogenous differences between cohorts in our model: the skill price (or the price per unit of human capital) and the fraction of workers who are college graduates. Skill price affects the start-of-work-life human capital of the college-educated workers; the fraction of college graduates affects the average ability of college-educated workers and high school- 
educated workers. Recent cohorts face a higher skill price, so the marginal return to human capital is higher. Hence college-educated workers in the recent cohort incur more expenditures and start their work lives with higher human capital. The Ben-Porath model then implies that the earnings growth for such workers would be less in the recent cohort. Recent cohorts also have a higher fraction of workers who are college graduates, so the average ability, conditional on education, is lower in the recent cohort. Given that the direct effect of ability dominates, the Ben-Porath model then implies that on-the-job human capital is accumulated at a slower rate in the recent cohort by both the high school and college educated and hence the earnings growth is less for both groups.

Quantitatively, our model implies 22.6 percent flattening of the earnings profiles for high school graduates and 15 percent for college graduates. Thus, our model accounts for more than 55 percent of the observed flattening for both high school graduates $(22.6 / 40.7=55.5$ percent) and college graduates. In our model, selection, or the ability threshold for college graduates (measured by the fraction of college graduates), plays an important quantitative role. If the fraction of college graduates in the 1980 cohort were the same as that in the 1940 cohort, then our model would imply no flattening for high school graduates and barely 6 percent flattening for college graduates, or less than 23 percent of the observed flattening.

Our paper is related to Kambourov and Manovskii (2009), Guvenen and Kuruscu (2010), Hendricks (2015), and Jeong, Kim, and Manovskii (2015), who also document the flattening of earnings profiles of successive cohorts of workers. Our evidence goes farther back, starting with the 1920 birth cohort. Their models involve demographic changes, changes in occupational mobility, or skill-biased technical change. We propose a different, simple model of the flattening that is also consistent with the increase in college attainment.

\section{THE MODEL}

In our model, individuals live for two periods, age 1 and age 2 . They differ in their ability, $a$, which is endowed to them in age 1 and remains constant throughout their lives. Ability, $a$, is distributed in the population according to the distribution function $A(a)$.

Each worker is endowed with a high school education and human capital $h_{1}(a)$, which is an increasing function of ability. We partition, exogenously, the population of workers into two groups. One, which we refer to as high school educated, starts working at the beginning of the first period with human capital $h_{1}(a)$. The other group, which we refer to as college educated, spends a fraction $s$ of the first period acquiring a college education. This group can choose to spend resources to enhance the quality of their college education. Specifically, the human capital of individuals in this group after college is produced via the technology $G\left(k, h_{1}(a), a\right)$, where $h_{1}(a)$ is their endowed initial human capital and $k$ represents goods spending. We assume that $G_{1}\left(k, h_{1}(a), a\right)$ is increasing in $a$.

Workers can accumulate human capital on the job, in the spirit of Ben-Porath (1967). The technology for accumulating human capital on the job is $F(n h, a)$, where $n \in(0,1]$ is time spent in human capital accumulation and $h$ is human capital at the start of work life. We assume that $F$ exhibits diminishing returns to $n h$ and that $F_{1}(n h, a)$ is increasing in $a$. 
We assume that the skill price, $w$ (i.e., the price per unit of human capital), grows exogenously at rate $g$. There are perfect credit markets where workers can borrow and lend freely at the interest rate $r$. On-the-job human capital depreciates at rate $\delta$.

The optimization problem of a high school-educated worker is

$$
\begin{gathered}
J^{\mathrm{HS}}(a)=\max _{n} w h^{\mathrm{HS}}(1-n)+\frac{1+g}{1+r} w\left[(1-\delta) h^{\mathrm{HS}}+F\left(n h^{\mathrm{HS}}, a\right)\right], \\
\text { s.t. } h^{\mathrm{HS}}=h_{1}(a) .
\end{gathered}
$$

The optimization problem of a college-educated worker is

$$
J^{\mathrm{CO}}(a)=\max _{k}\left\{\max _{n} w h^{\mathrm{CO}}(1-s-n)+\frac{1+g}{1+r} w\left[(1-\delta) h^{\mathrm{CO}}+F\left(n h^{\mathrm{CO}}, a\right)\right]\right\}-k,
$$

$$
\text { s.t. } \quad h^{\mathrm{CO}}=G\left(k, h_{1}(a), a\right) \text {. }
$$

Note that the inner maximization in problem (3) is similar to the maximization in problem (1). It represents the worker's choice to accumulate human capital on the job. There are two differences between these two problems. First, college-educated workers have already spent a fraction $s$ of their first period of life in college. They have only $1-s$ units of time left to work or learn on the job, while high school-educated workers have 1 unit of time. Second, the human capital at the start of work life is not the same for high school- and college-educated workers. The former start with their endowed human capital $h^{\mathrm{HS}}=h_{1}(a)$, while the latter start with $h^{\mathrm{CO}}$, which is a choice variable and depends on the amount of expenditures in college. The outer maximization in problem (3) describes the choice of goods spending in college.

\subsection{Decisions}

The first-order condition for $n$ is the same for high school- and college-educated workers:

$$
w h=\frac{1+g}{1+r} w h F_{1}(n h, a), h=h^{H S}
$$

and

$$
w h=\frac{1+g}{1+r} w h F_{1}(n h, a), h=h^{C O},
$$

where in each equation $h$ is the human capital at the start of work life, the left-hand side is the marginal cost of increasing $n$, and the right-hand side is the discounted marginal benefit. $\underline{3}$ The start-of-work-life human capital $h^{\mathrm{HS}}$ is exogenous, but $h^{\mathrm{CO}}$ is endogenous (see below).

Two points are worth noting here. First, the optimal value of $n$ determined by equation (5) or (6) is decreasing in $h$ : Higher $h$ implies lower human capital accumulation on the job due to diminishing returns to $n h$. Thus, individuals with higher start-of-work-life human capital have less earnings growth. Second, the optimal $n$ is increasing in ability since $F_{1}(n h, a)$ is increasing in $a$. 
The start-of-work-life human capital for college-educated workers, $h^{\mathrm{CO}}$, is determined by the optimal choice of expenditures, $k$, in college. The first-order condition for $k$ is

$$
1=w\left(1-s+\frac{1+g}{1+r}(1-\delta)\right) G_{1}\left(k, h_{1}(a), a\right),
$$

where the left-hand side is the marginal cost of college spending and the right-hand side is the marginal benefit, both measured in goods. Equation (7) implies that the optimal goods spending in college is increasing in the skill price, $w$, and in ability, $a$. Thus, conditional on $w$, individuals with higher ability acquire more human capital in college (higher $h^{\mathrm{CO}}$ ), and, conditional on ability, individuals facing a higher skill price also acquire more human capital in college.

\section{MODEL MECHANICS}

Two exogenous variables characterize a cohort in our model. One is the partition of workers between high school- and college-educated workers. To operationalize this partition, we assign a threshold value of ability, $a^{*}$, and assign education according to

$$
\text { Education }= \begin{cases}\text { High school } & \text { if } a<a^{*} \\ \text { College } & \text { if } a \geq a^{*} .\end{cases}
$$

The proportion of workers with a college education is given by $1-A\left(a^{*}\right)$. The ability distribution is assumed to be constant across cohorts, so the cohort with more college-educated workers is characterized by a lower value of $a^{*}$.

The other exogenous difference between cohorts is the level of the skill price, $w$, at the start of the work life. The growth rate of the skill price, $g$, is the same for each cohort. Each cohort is thus characterized by two numbers, $a^{*}$ and $w$. Differences across cohorts in $a^{*}$ and $w$ generate differences in earnings growth of high school- and college-educated workers in each cohort.

\subsection{Human Capital and Earnings Growth}

Figure 1 presents a stylized description of the key outcomes of our model for either cohort. In the top panel, the line describes human capital at the start of the work life for high schooland college-educated workers. For high school-educated workers, the line plots the function $h_{1}(a)$ up to the threshold $a^{*}$; for college-educated workers, the line plots the function $G\left(k, h_{1}(a), a\right)$ at the optimal value of $k$ from problem (3), above the threshold $a^{*}$. Note the discontinuity at $a^{*}$ : The marginal worker would start work with more human capital after a college education.

In the bottom panel, the line describes earnings growth over the life cycle. Two points noted in Section 1.1 are worth repeating. First, conditional on education, earnings growth is increasing in ability. This is mainly due to the assumption that $a$ positively affects human capital accumulation on the job. There is an opposing force, however. Human capital at the start of work life is increasing in $a$ for both high school-educated and college-educated workers, 
Figure 1

Human Capital and Earnings Growth in a Cohort

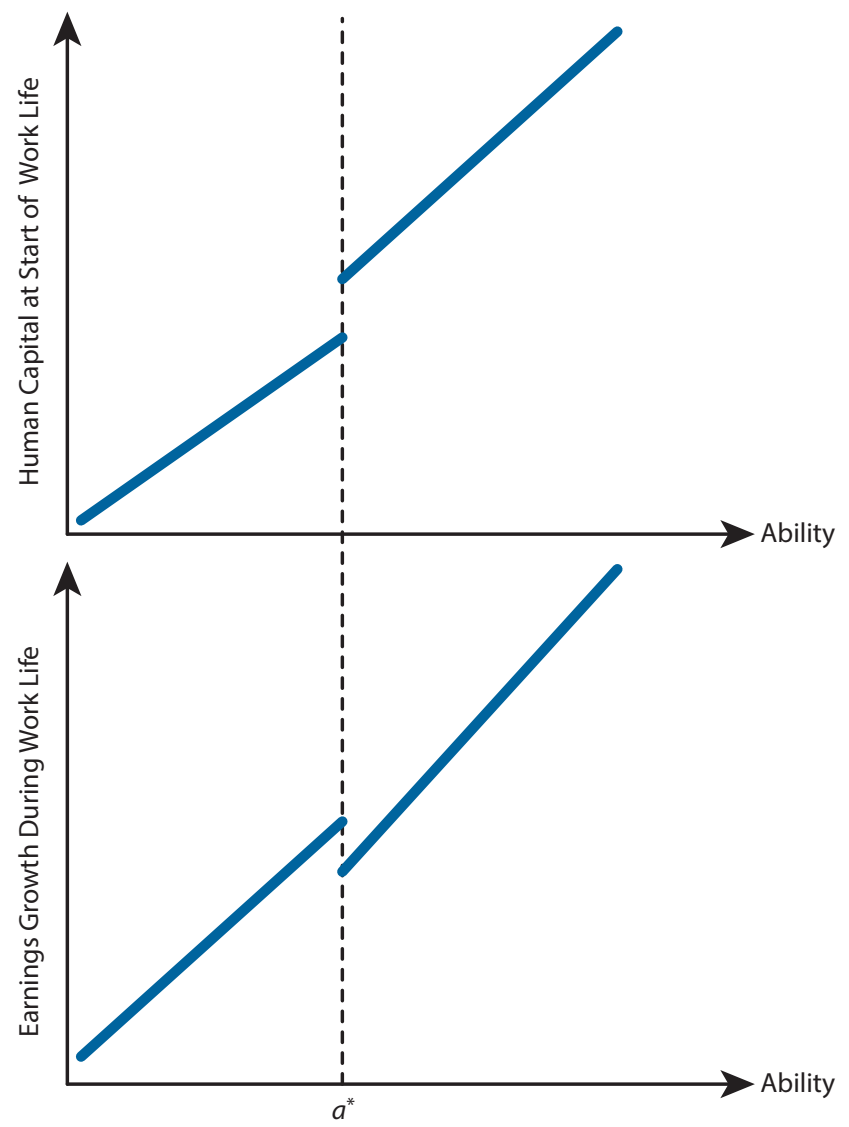

and the diminishing-returns property of $F$ implies lower returns to human capital accumulation on the job. This effect may or may not be offset by the direct effect of ability. In Figure 1 we assume that the direct effect of ability offsets the return effect. This is also true in our quantitative exercise of Section 3.

Second, there is a discontinuity at $a^{*}$. The marginal worker would experience less earnings growth if he attended college than if he was high school educated only. This is because after a college education the marginal worker would start working with more human capital (top panel). This implies lower returns to human capital accumulation on the job and, in turn, less human capital accumulation and less earnings growth.

To compute the growth in average earnings of high school- and college-educated workers, we proceed as follows. Let $E_{j}^{i}(a)$ denote the earnings of an age $j$ worker with ability $a$ and education $i \in\{\mathrm{HS}, \mathrm{CO}\}$. Then,

$$
E_{j}^{\mathrm{HS}} \equiv \int_{0}^{a^{*}} E_{j}^{\mathrm{i}}(a) A(d a)
$$


Figure 2

Cross-Cohort Differences: The Effect of Higher College Attainment, Holding the Skill Price Constant

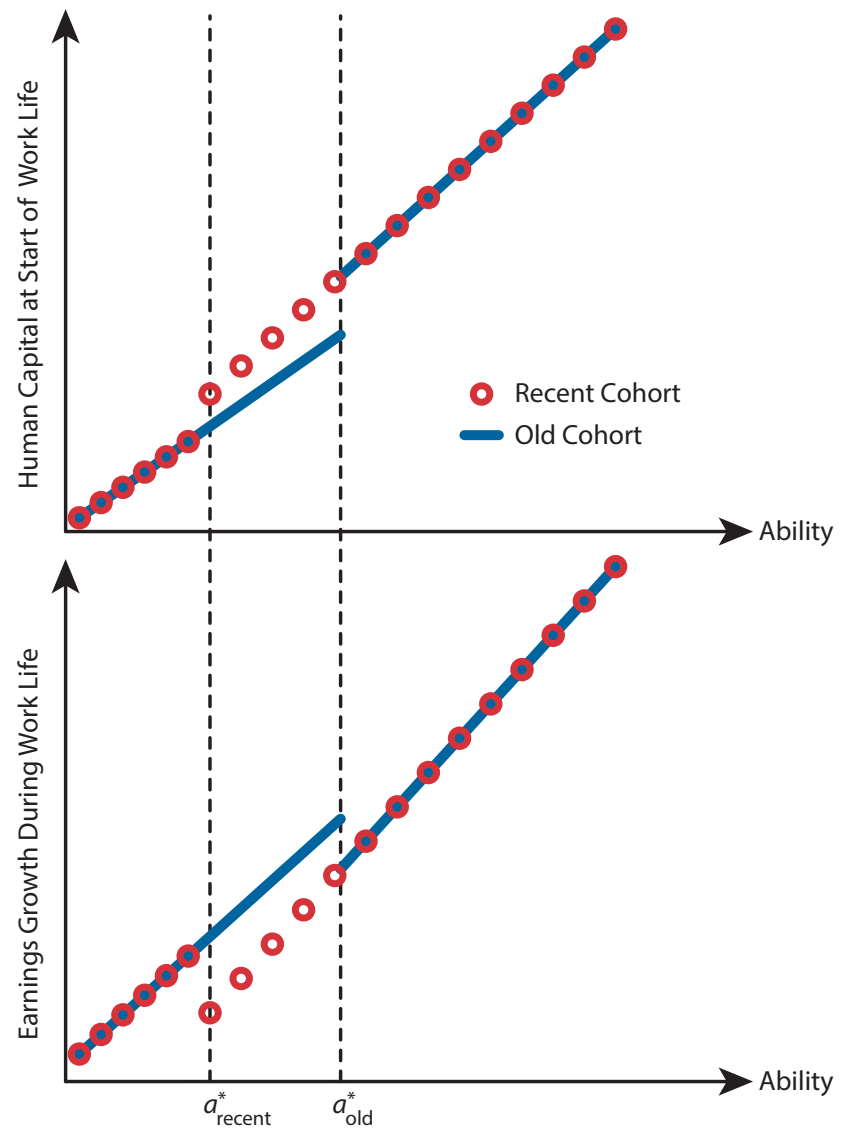

and

$$
E_{j}^{\mathrm{CO}} \equiv \int_{a^{*}} E_{j}^{\mathrm{i}}(a) A(d a)
$$

In line with our definition of earnings growth in the Introduction, we measure earnings growth for workers with education $i$ by $E_{2}^{i} / E_{1}^{i}$.

\subsection{The Effect of College Attainment}

Consider two cohorts, recent and old, that differ in the fraction of college-educated workers but face the same value for $w$. The recent cohort is characterized by a higher fraction of college-educated workers:

$$
a_{\text {recent }}^{*}<a_{\text {old }}^{*}
$$


Figure 3

\section{Cross-Cohort Differences: The Effect of Higher Skill Price, Holding College Attainment Constant}

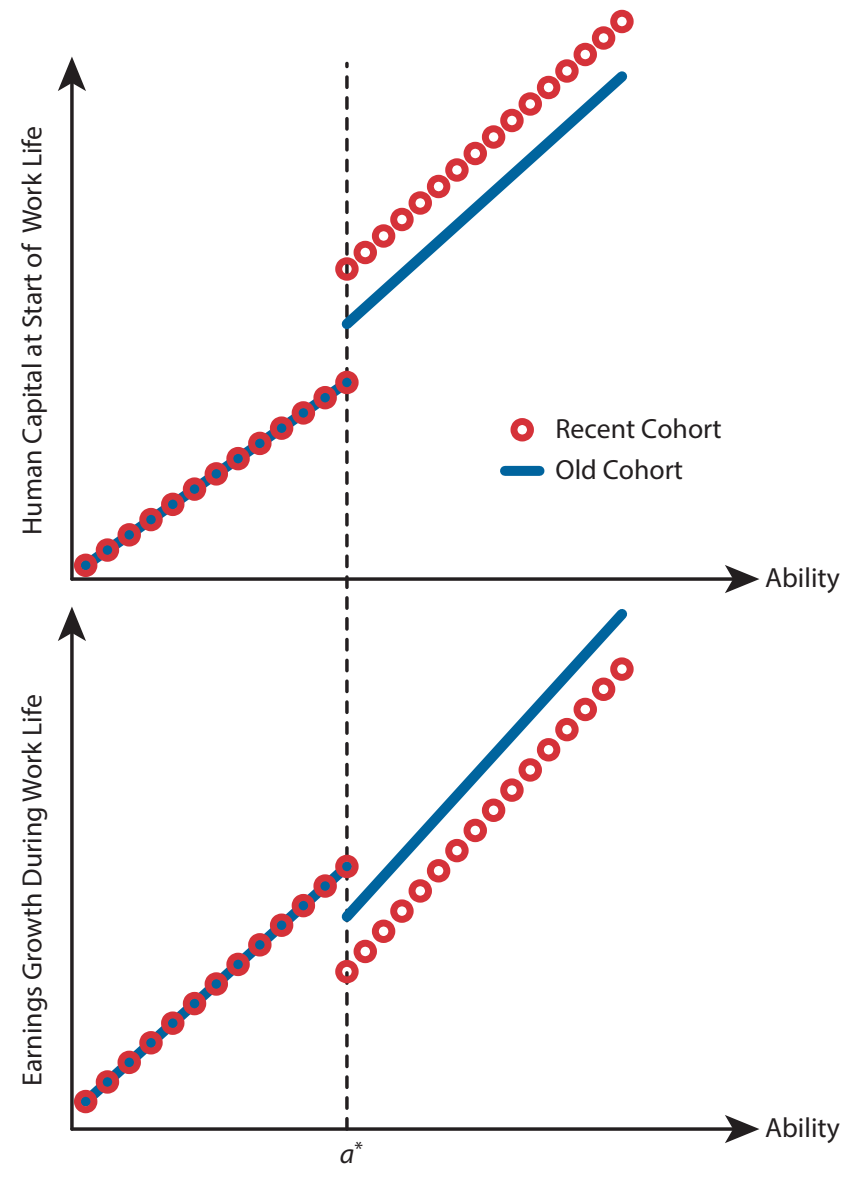

Figure 2 describes how human capital at the start of the work life and earnings growth differ for the two cohorts. The blue lines refer to the old cohort. The red circles refer to the recent cohort.

We adopt the following terminology: "always high school" is those workers with ability levels $a$ such that $a<a_{\text {recent }}^{*}$ and "always-college" is those with ability levels $a$ such that $a>a_{\text {old }}^{*}$. We use the term "switchers" to refer to those with ability $a \in\left[a_{\text {recent }}^{*}<a_{\text {old }}^{*}\right]$.

Note in Figure 2 that the human capital and earnings growth of always-high-school and always-college workers are the same for both cohorts. This is because these workers face exactly the same environment in the old and the recent cohorts. The switchers, however, acquire a college education in the recent cohort. As a result of a college education, they start their work lives with more human capital than their counterparts in the old cohort (top panel), which implies lower earnings growth over the life cycle (bottom panel). 
It is clear from Figure 2 that the average earnings growth of both high school- and collegeeducated workers is lower in the recent cohort than in the old cohort. An increase in college attainment, therefore, implies a flattening of the average earnings profile of both high schooland college-educated workers. This is one channel for flattening in our model.

\subsection{The Effect of Skill Price Growth}

Consider now two cohorts that have the same college attainment but face different values for the skill price, $w$. With positive skill price growth, the recent cohort faces a higher value of $w$. Figure 3 describes the effects of this experiment.

Observe that human capital and earnings growth are the same for the high school-educated in both cohorts. This is because the environment for these workers is the same regardless of the level of $w$-this is clear from an inspection of problem (1). For college-educated workers, the level of the skill price in age 1 matters. A higher skill price implies goods are relatively cheaper, so the recent cohort would incur higher goods spending in college and, hence, finish college with more human capital (top panel). This implies, in turn, lower earnings growth for college-educated workers of the recent cohort (bottom panel).

It is thus clear from Figure 3 that the average earnings growth of high school-educated workers is the same in both cohorts and is not affected by the higher skill price. The average earnings growth of college-educated workers, however, is lower in the recent cohort since they start their work life with more human capital. This is the second channel for flattening in our model.

\section{QUANTITATIVE IMPLICATIONS}

We compare the life-cycle earnings profiles of workers in the 1940 and the 1980 cohorts. We measure flattening, as in Table 1, by the percentage change in the earnings growth over the life cycle; that is,

$$
100 \times\left(1-\frac{E_{2,1980}^{\mathrm{HS}} / E_{1,1980}^{\mathrm{HS}}}{E_{2,1940}^{\mathrm{HS}} / E_{1,1940}^{\mathrm{HS}}}\right)
$$

for high school-educated workers and

$$
100 \times\left(1-\frac{E_{2,1980}^{\mathrm{CO}} / E_{1,1980}^{\mathrm{CO}}}{E_{2,1940}^{\mathrm{CO}} / E_{1,1940}^{\mathrm{CO}}}\right)
$$

for college-educated workers.

\subsection{Calibration}

The functional forms for the human capital technologies are

$$
h_{1}(a)=a,
$$




$$
\begin{gathered}
G\left(k, h_{1}(a), a\right)=\left(z_{G} k\right)^{\eta}\left(a h_{1}(a)\right)^{1-\eta}, \\
F(n h, a)=z_{F} a(n h)^{\phi} .
\end{gathered}
$$

The model period is 20 years. The rate of interest, $r$, is 5 percent per year. The rate of depreciation, $\delta$, is 1 percent per year, similar to Huggett, Ventura, and Yaron (2006). The elasticity parameter in Equation (12) is $\phi=0.75$; this is in the range of estimates reported by Browning, Hansen, and Heckman (1999). The growth rate of the skill price is 1.15 percent per year, the average growth rate used by Kong, Ravikumar, and Vandenbroucke (2016). The time spent in college is $s=4 / 20$. The distribution of ability is log-normal:

$$
\ln a \sim N(\mu, \sigma)
$$

Finally, we choose $a_{1940}^{*}$ and $a_{1980}^{*}$ such that 30 percent of workers have a college education in the 1940 cohort and 50 percent in the 1980 cohort. These fractions correspond to college attainment for these cohorts in the U.S. data.

We adopt the normalization $\mu=0$. The remaining parameters are $z_{F}, z_{G}, \sigma$, and $\eta$. To choose these parameters, we minimize the distance between moments implied by the model for the earnings of the 1940 cohort and their empirical counterparts. The moments we use are (i) earnings growth for the high school-educated workers; (ii) earnings growth for the college-educated workers; (iii) the coefficient of variation of earnings at age 2 for the high school-educated workers; and (iv) the coefficient of variation of earnings at age 2 for the college-educated workers. The empirical values of the first two moments are reported in Table 1. The empirical values for the last two moments are 0.5 and 0.6 , respectively (see Kong, Ravikumar, and Vandenbroucke, 2016, Table 3).

\subsection{Results}

Table 2 reports the calibrated parameters. Table 3 reports our main results. Observe that the model implies earnings growth for the 1940 cohort that are the same as in the data. Although this is a target of the calibration, it should be noted that the earnings growth of a given cohort combines two effects. The first effect is the exogenous growth in the skill price: 1.15 percent per year. The second effect is the accumulation of human capital on the job. The annualized earnings growth rates in the model (and in the data) for the 1940 cohort are 4.3 percent and 5 percent per year for high school- and college-educated workers, respectively. Thus, the skill price growth is amplified nearly fourfold by the endogenous human capital accumulation in the model.

Comparing the 1940 and 1980 cohorts, the model delivers 22.6 percent flattening for the high school-educated workers; the corresponding figure in the data is 40.7 percent. Thus, the model accounts for 55.5 percent of the observed flattening for the high school-educated workers $(22.6 / 40.7=55.5$ percent $)$. Similarly, the model delivers 15 percent flattening for college-educated workers. The figure in the data is 26.9 percent, so the model accounts for 55.7 percent of the observed flattening for college-educated workers. 


\section{Table 2}

\section{Calibration}

\begin{tabular}{|c|c|c|}
\hline \multicolumn{3}{|l|}{ A priori parameters } \\
\hline Interest rate (annualized) & $r=0.05$ & \\
\hline Depreciation (annualized) & $\delta=0.01$ & \\
\hline Education & $s=0.20$ & \\
\hline Ability distribution & $\mu=0.00$ & \\
\hline On-the-job technology & $\phi=0.75$ & \\
\hline Skill price growth (annualized) & $g=0.0115$ & \\
\hline \multicolumn{3}{|l|}{ Calibrated parameters } \\
\hline Ability distribution & $\sigma=0.31$ & \\
\hline College technology & $z_{G}=13.53, \eta=0.42$ & \\
\hline On-the-job technology & $z_{F}=2.51$ & \\
\hline Targeted moments (1940 cohort) & Data & Model \\
\hline \multicolumn{3}{|l|}{ High school educated } \\
\hline Earnings growth & 2.22 & 2.22 \\
\hline Coefficient of variation of earnings & 0.5 & 0.4 \\
\hline \multicolumn{3}{|l|}{ College educated } \\
\hline Earnings growth & 2.52 & 2.52 \\
\hline Coefficient of variation of earnings & 0.6 & 0.6 \\
\hline
\end{tabular}

\section{Table 3}

\section{Baseline Results}

\begin{tabular}{lcc} 
& High school & College \\
\hline 1940 Cohort earnings growth & 2.22 & 2.52 \\
\hline 1980 Cohort earnings growth & 1.72 & 2.14 \\
\hline \% Flattening & 22.6 & 15.0 \\
\hline Flattening relative to data & 55.5 & 55.7 \\
\hline
\end{tabular}

\section{Table 4}

\section{Counterfactual Experiment: No Change in College Attainment}

\begin{tabular}{lcc} 
& High school & College \\
\hline 1940 Cohort earnings growth & 2.22 & 2.52 \\
\hline 1980 Cohort earnings growth & 2.22 & 2.36 \\
\hline Flattening & 0.0 & 6.1
\end{tabular}


Table 4 reports a decomposition: How much of the flattening implied by the model is due to selection? To answer this question, we hold college attainment to be the same in both cohorts. Specifically, the fraction of college-educated workers in the 1980 cohort is set at 30 percent, which is the observed fraction for the 1940 cohort. The skill price at the start of work life for the 1980 cohort is higher than that for the 1940 cohort, since the skill price grows annually at 1.15 percent. With college attainment the same for the two cohorts, the model implies no flattening for high school-educated workers (as noted in Figure 3) and only 6.1 percent flattening for college-educated workers. That is, without selection, the model accounts for none of the observed flattening for high school-educated workers and only 22.7 percent for college-educated workers.

\section{CONCLUDING REMARKS}

We document that life-cycle earnings profiles are getting flatter. For instance, the life-cycle earnings profile was about 41 percent flatter for high school-educated workers in the 1980 cohort relative to those in the 1940 cohort. And for college-educated workers in the 1980 cohort it was about 27 percent flatter relative to those in the 1940 cohort.

We develop a simple, two-period model of human capital accumulation on the job and through college attainment. We use a calibrated version of the model to explain the observed flattening of the life-cycle earnings profiles of two cohorts of workers. Our model accounts for more than 55 percent of the observed flattening for high school graduates and for college graduates. Two channels generate the flattening in our model: selection (or higher college attainment) and a higher skill price for the recent cohort. Absent selection, the model would have accounted for less than 23 percent of the observed flattening.

In our analysis, college enrollment is exogenous. Kong, Ravikumar, and Vandenbroucke (2016) present a multi-period life-cycle model where workers optimally choose whether to be college educated or not. Workers with ability above a (endogenously determined) threshold choose to become college educated and those below the threshold choose not to. Disciplining the model to match the time trend in college enrollment, they examine the flattening of lifecycle earnings profiles using cross-cohort differences in the skill price. 


\section{NOTES}

1 A period of working life is 20 years long in our calculations. The numbers in Table 1 correspond to a 4.3 percent annual rate of real earnings growth for high school-educated workers and 5 percent for college-educated workers.

$\underline{2}$ The numbers in Table 1 are based on synthetic cohorts of employed white men using Census data.

$\underline{3}$ A corner solution is possible. In this case, $n=1$ for high school-educated workers and $n=1-s$ for college-educated workers. For our quantitative exercise in Section 3, the corner cases are not relevant.

\section{REFERENCES}

Ben-Porath, Yoram. "The Production of Human Capital and the Life-Cycle of Earnings." Journal of Political Economy, August 1967, 75(4), pp. 352-65; https://doi.org/10.1086/259291.

Browning, Martin; Hansen, Lars Peter and Heckman, James J. "Micro Data and General Equilibrium Models." Handbook of Macroeconomics. Volume 1. Part A. Elsevier, 1999, pp. 543-633; https://doi.org/10.1016/S1574-0048(99)01011-3.

Guvenen, Fatih and Kuruscu, Burhanettin. "A Quantitative Analysis of the Evolution of the U.S. Wage Distribution, 1970-2000," in D. Acemoglu, K. Rogoff and M. Woodford, eds., NBER Macroeconomics Annual 2009. Volume 24. National Bureau of Economic Research, April 2010, pp. 227-76; http://www.nber.org/chapters/c11798.pdf.

Heckman, James J.; Lochner, Lance and Taber, Christopher. "Explaining Rising Wage Inequality: Explorations with a Dynamic General Equilibrium Model of Labor Earnings with Heterogeneous Agents." Review of Economic Dynamics, January 1998, 1(1), pp.1-58; https://doi.org/10.1006/redy.1997.0008.

Hendricks, Lutz. "Accounting for Changing Returns to Experience." CFS Working Paper No. 558, Center for Financial Studies, October 2015; https://ssrn.com/abstract=2869179.

Huggett, Mark; Ventura, Gustavo and Yaron, Amir. "Human Capital and Earnings Distribution Dynamics." Journal of Monetary Economics, March 2006, 53(2), pp. 265-90; https://doi.org/10.1016/j.jmoneco.2005.10.013.

Huggett, Mark; Ventura, Gustavo and Yaron, Amir. "Sources of Lifetime Inequality." American Economic Review, 2011, 101(7), pp. 2923-54; https://doi.org/10.1257/aer.101.7.2923.

Jeong, Hyeok; Kim, Yong and Manovskii, lourii. "The Price of Experience." American Economic Association, February 2015, 105(2), pp. 784-815; https://www.aeaweb.org/articles?id=10.1257/aer.20080841.

Kambourov, Gueorgui and Manovskii, lourii. "Accounting for the Changing Life-Cycle Profile of Earnings." Working paper, University of Pennsylvania, October 2009;

http://economics.sas.upenn.edu/ manovski/papers/accounting for profiles.pdf.

Kong, Yu-Chien; Ravikumar, B. and Vandenbroucke, Guillaume. "Explaining Cross-Cohort Differences in Life Cycle Earnings." Working Paper No. 2015-035C, Federal Reserve Bank of Saint Louis, 2016;

https://research.stlouisfed.org/wp/more/2015-035. 
